\title{
Médiévales
}

Langues, Textes, Histoire

45 | automne 2003

Grammaires du vulgaire

\section{Bernard Guenée, L'Opinion publique à la fin du Moyen Âge d'après la «Chronique de Charles VI » du Religieux de Saint-Denis}

Paris, Perrin, 2002, 270 p., index des noms de personnes et de lieux

\section{Vincent Challet}

\section{OpenEdition}

\section{Journals}

Édition électronique

URL : https://journals.openedition.org/medievales/964

DOI : 10.4000/medievales.964

ISSN : $1777-5892$

Éditeur

Presses universitaires de Vincennes

Édition imprimée

Date de publication : 16 septembre 2003

Pagination : 183-185

ISBN : 2-84292-146-1

ISSN : 0751-2708

\section{Référence électronique}

Vincent Challet, «Bernard Guenée, L'Opinion publique à la fin du Moyen Âge d'après la "Chronique de Charles VI » du Religieux de Saint-Denis », Médiévales [En ligne], 45 | automne 2003, mis en ligne le 08 décembre 2005, consulté le 22 avril 2022. URL : http://journals.openedition.org/medievales/964 ; DOI : https://doi.org/10.4000/medievales.964

Ce document a été généré automatiquement le 22 avril 2022

Tous droits réservés 


\title{
Bernard Guenée, L'Opinion publique à la fin du Moyen Âge d'après la "Chronique de Charles VI» du Religieux de Saint-Denis
}

Paris, Perrin, 2002, 270 p., index des noms de personnes et de lieux

\author{
Vincent Challet
}

1 Ce n'est certes pas la première fois que Bernard Guenée, éminent historien du politique, se penche sur cette Chronique de Charles VI que composa Michel Pintoin, chantre de l'abbaye de Saint-Denis. Outre la remarquable préface à la réédition de cette œuvre publiée par les soins du Comité des Travaux Historiques et Scientifiques (CTHS) en 1994, Bernard Guenée lui avait déjà consacrée de nombreuses études reprises récemment dans Un roi et son historien et le colloque qui s'était tenu en son honneur à Saint-Denis en 1996 autour de Saint-Denis et la royauté avait fait une large place à cette œuvre que l'on a longtemps considérée - bien à tort comme le montre de nouveau Bernard Guenée - comme une chronique officielle. Nul n'était donc mieux placé pour proposer de ce texte une approche novatrice qui tend à envisager l'ouvrage de Michel Pintoin sous l'angle de l'opinion publique.

2 En effet, la chronique du Religieux de Saint-Denis se distingue à la fois de l'historiographie dionysienne et de la Chronique des règnes de Jean II et de Charles V composée par Pierre d'Orgemont à la demande de Charles V par une attention plus soutenue aux mouvements de l'opinion publique qui constituent à partir de la fin du $\mathrm{XIV}^{\mathrm{e}}$ siècle l'un des acteurs essentiels de l'histoire du royaume de France. Ce souci est incontestablement l'une des grandes originalités de l'œuvre de Michel Pintoin et l'auteur s'attache à relever les variations parfois infimes de vocabulaire qui reflètent dans le récit du chroniqueur l'état de cette opinion, à laquelle les princes du temps, soucieux de ne pas en faire les frais, accordent la plus grande attention. Et, comme le montre l'auteur, c'est précisément lorsque l'opinion publique devient acteur de l'histoire, que se développe de façon concomitante l'art de la propagande politique qui, 
maniée avec tout le discernement dont sut faire preuve Jean sans Peur dans la querelle qui l'opposait à Charles d'Orléans, permet d'emporter la décision lorsque les armes se montrent impuissantes.

3 Adoptant une démarche comparable à celle, entre autres, de Gerd Althoff pour qui les émotions ont une fonction sociale, Bernard Guenée se fait d'abord historien des émotions, de ces émotions qui animent aussi bien les princes que le peuple et qui s'expriment en premier lieu dans le cadre de ces rituels bien connus désormais que sont les acclamations royales ou les processions. Mais plus encore que l'amour que le peuple porte à son roi ou que la joie qu'il lui manifeste à l'occasion de cérémonies suscitées par le pouvoir royal, c'est la haine qui occupe une place prépondérante tant dans l'œuvre de Michel Pintoin que tout au long du règne de Charles VI: haine inexpiable et inextinguible que se vouent les ducs de Bourgogne et d'Orléans, haine réciproque des Anglais et des Français, haine du menu peuple pour ceux qui le gouvernent. La haine constitue bien "une donnée essentielle de la vie politique » (p. 69) et l'auteur s'attache à montrer comment le Religieux de Saint-Denis, dans une subtile gradation qui va du murmure à l'injure ouverte, rend compte des diverses manifestations de cette haine.

4 À cette première grille d'analyse, l'auteur en superpose une seconde qui permet de cerner les différents groupes que le Religieux de Saint-Denis met en scène dans sa chronique. Certes, les habitants du royaume (regnicole, Francigene, Franci) parlent parfois d'une même voix comme lorsqu'il s'agit en 1386 de se réjouir de la naissance du fils aîné de Charles VI. Mais le plus souvent et tout particulièrement pendant la longue période de guerre civile qui s'ouvre en 1407 aux lendemains de l'assassinat du duc d'Orléans, l'opinion publique du royaume se divise. Tout en bas de l'échelle sociale se situent les paysans, les bouchers, les artisans, ces hommes les plus vils (vilissimi et abjectissimi homines) qui poussés par le diable sont responsables de la flambée révolutionnaire qui se déclenche sous le règne de Charles VI. Mais comme le dit Bernard Guenée, "ce qu'ils pensent n'intéresse pas " le Religieux de Saint-Denis (p. 101). Le clivage fondamental de la société est, pour Michel Pintoin, celui qui existe entre "gens d'autorité » et "gens de commun » et l'auteur, par un habile détour du côté des théories politiques de la fin du XIV siècle, montre ce que doit ici le chroniqueur aux penseurs issus du Collège de Navarre (Nicole Oresme, Jean de Montreuil, Jean Gerson) lorsqu'il s'agit de préciser l'élite à laquelle doit revenir le gouvernement du royaume. L'autorité est bien une "notion clé qui définit l'élite» (p. 132) mais la défaillance du pouvoir politique face aux crises que traverse le royaume rend en partie cette définition caduque en démontrant que les « gens d'autorité » n'ont pas nécessairement les qualités nécessaires au bon gouvernement de la chose publique. En fin de compte, dans l'esprit du Religieux de Saint-Denis, l'élite est perçue comme un groupe de "gens d'autorité qui ont la réputation d'être sages» (p. 145), tant la notion de sagesse occupe chez le chantre de Saint-Denis une position centrale. Ces sages (circumspecti) considérés comme un groupe à part entière sont l'un des acteurs essentiels de l'œuvre de Michel Pintoin qui met fréquemment en relief dans sa chronique leurs jugements et leur donne un poids qu'ils n'eurent sans doute pas dans la réalité. En ce sens, comme le montre admirablement bien Bernard Guenée, la chronique du Religieux de Saint-Denis est incontestablement « une chronique des sages » (p. 180), de ces sages qui voient avec effroi le monde de leurs certitudes sombrer dans la guerre civile. Et si l'on peut dire que la Chronique de Charles VI est une chronique d'opinion, 
encore faut-il préciser qu'elle est surtout le reflet de l'opinion de ceux que Michel Pintoin a pris soin de désigner comme sages.

Mais l'on touche ici aux limites de cette exercice : la chronique du Religieux de SaintDenis est en effet une chronique locale, celle de Paris, et France rurale et France méridionale sont les grands muets de cette partition à plusieurs voix à laquelle le chantre de Saint-Denis nous convie. Même lorsque ce dernier utilise des expressions qui, à première vue, englobent l'ensemble des habitants du royaume - ainsi les Francigeni - il n'entend guère par là que les habitants du Nord de la France : ce sont bien des Francigeni qui, en 1384, viennent à bout en Auvergne de la révolte des Tuchins. Le Tuchinat constitue d'ailleurs le seul moment de la chronique où les paysans deviennent les acteurs de leur propre histoire et le terme même de paysan n'apparaît, sous la plume de Bernard Guenée, qu'à propos de cet événement, exceptionnel à plus d'un titre. Pour Michel Pintoin, France méridionale et France rurale n'existent que dans la mesure où l'écho de leur révolte parvient jusqu'à Saint-Denis. Ainsi, l'une des ambitions du chantre de Saint-Denis était d'être «le porte-parole des sages» (p. 178), ce qui constitue l'une des principales originalités de sa chronique mais en marque en même temps les limites. Et ce n'est pas le moindre mérite du livre de Bernard Guenée que de nous indiquer ce que l'on est en droit d'attendre - ou de ne pas attendre - d'un tel récit. Maintenant que voici posé le premier jalon d'une étude de l'opinion publique à la fin du Moyen Âge, souhaitons seulement que d'autres enquêtes viennent compléter et nuancer le tableau qui nous est proposé ici. 